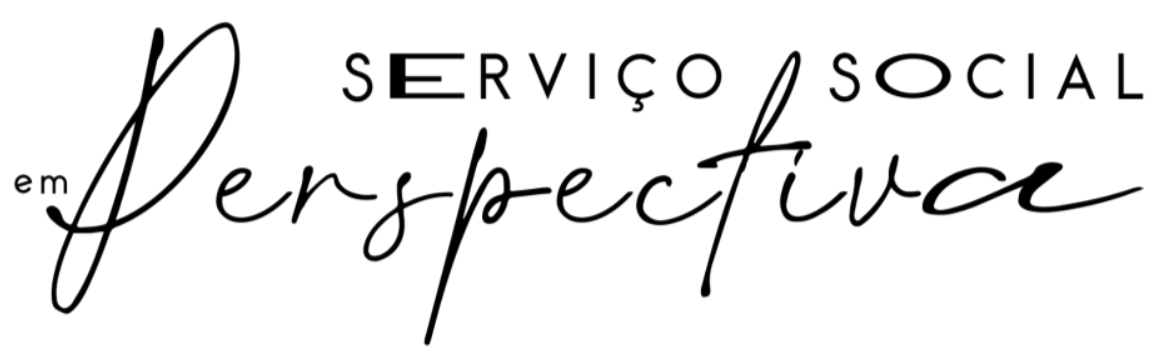

Montes Claros (MG), volume 5, número 1. jan./jun. 2021. I ISSN 2527-1849

\title{
CONSULTÓRIO DE RUA DE BELO HORIZONTE E OS DESAFIOS ENFRENTADOS NA PANDEMIA DO COVID-19.'
}

\author{
STREET OFFICE OF BELO HORIZONTE AND THE CHALLENGES FACED IN PANDEMIA OF \\ COVID-19.
}

Ana Carolina de Freitas Campos ${ }^{2}$

Aruã Siman Alves de Resende 3

\begin{abstract}
Resumo: O presente artigo traz o debate sobre a atuação do Consultório de Rua de Belo Horizonte durante o periodo da pandemia do COVID19. Por ser um equipamento de saúde volante. muitas práticas de processos de trabalho tiveram que ser repensadas para que o cuidado continuasse a ser garantido. Entretanto há uma fragilidade importante nas politicas sociais que envolvem a população em situação de rua e que ficaram mais evidentes nesse momento de crise sanitária. econômica e social que estamos vivenciando. mostrando a imensa lacuna que ainda temos na garantia dos direitos sociais das populações vulnerabilizadas.
\end{abstract}

Palavras-chave: pandemia; população em situação de rua; saúde.

Abstract: This article discusses the performance of the Belo Horizonte Street Clinic during the COVID19 pandemic. As it is a mobile health equipment. many practices had to be rethought so that care would be guaranteed. However, there is an important weakness in the social policies related to the homeless population and that was more evident in this moment of sanitary, economic and social crisis that we are experiencing. showing the immense gap that we still have in guaranteeing the social rights of the vulnerable populations.

Keywords: pandemic; homeless population; health.

\footnotetext{
'Este trabalho é um relato de experiência a partir do trabalho no Consultório de Rua de Belo Horizonte. equipe Oeste. no momento da Pandemia do COVID-19. Não foi financiado e também não é resultado de dissertação de mestrado ou tese de doutorado.

${ }^{2}$ Assistente Social, graduada pela Pontificia Universidade Católica de Minas, especialista em urgência e trauma pela residência multiprofissional do Hospital Odilon Behrens. Mestranda do programa Promoção à saúde e prevenção da violência da Universidade Federal de Minas Gerais. Assistente Social do Consultório de Rua Oeste e do Centro de Referência em Saúde Mental para usuários de álcool e drogas Barreiro da Prefeitura Municipal de Belo Horizonte. E-mail:carolfreitascampos@hotmail.com.

3 Psicólogo graduado pela Universidade Federal de Minas Gerais, psicólogo do Consultório de Rua de Belo Horizonte. equipe Oeste da Prefeitura Municipal de Belo Horizonte. Membro da Associação Traço: Associação Livre em Psicanálise. Psicólogo clinico em consultório particular. E-mail: aruasiman@gmail.com

Artigo submetido em: 18 de outubro de 2020.

Artigo aceito em: 30 de novembro de 2020.

p. 151-160 DOI: https://doi.org/10.46551/rssp202110
} 
INTRODUÇÃO

Atrelado ao processo de redemocratização ocorrido no Brasil nos anos 1980, surgiram os movimentos da Reforma Sanitária e da Reforma Psiquiátrica, trazendo uma nova e mais abrangente compreensão do significado de saúde. Por meio da organização política e mobilização do controle social, a população conquistou vários direitos sociais que estão expressos na Constituição Federal de 1988, e também nas Leis 8.080 e 8.142, ambas de 1990 , que dispõe acerca do Sistema Único de Saúde.

\section{A saúde é direito de todos e dever do Estado, garantido mediante políticas sociais e econômicas que visem à redução do risco de doença e de outros agravos e ao acesso universal igualitário às ações e serviços para sua promoção, proteção e recuperação (Brasil, 1988).}

Apesar do direito garantido constitucionalmente desde 1988, sabe-se que não são todos os brasileiros que possuem o acesso de forma integral e igualitária. Essa situação é ainda mais inquietante quando se trata de grupos em situação de alta vulnerabilização, como as pessoas em situação de rua.

Somente em 2011. com a implementação da Política Nacional de Atenção Básica em Saúde (PNAB), a concepção dos Consultórios na Rua foi concretizada, através da Portaria № 122. de 25 de Janeiro de 2011, que define as diretrizes de organização e funcionamento das equipes de Consultório na Rua (Brasil, 2011). O Consultório de Rua (CdeR) é um equipamento volante do Sistema Único de Saúde (SUS), que atua de forma territorializada, possibilitando e criando estratégias para o cuidado em saúde da população em situação de rua, por meio do acesso aos serviços de saúde, da Política de Redução de Danos, do acesso à cultura e da circulação dos sujeitos na cidade, propondo um cuidado de forma integral e enxergando o individuo na sua totalidade. Nesse sentido, é possivel perceber que o CdeR, na construção do caso a caso, retira os holofotes sobre as drogas, entendendo que são sujeitos com dores, amores e que estabelecem modos diversos de estar e existir no mundo.

A construção de um cuidado em saúde é estabelecida, partindo do princípio da singularidade e da construção de um projeto que reconhece esses sujeitos com seus desejos e potenciais a serem desenvolvidos, sempre direcionando o cuidado para aquilo que o usuário aponta como saida e possibilidade, co-construindo respostas para suas questões.

Atualmente, há no município de Belo Horizonte quatro equipes de Consultório de Rua. Essas equipes atuam nas regionais Centro-Sul, Noroeste, Norte e Oeste, compostas por uma 
equipe multiprofissional, com seis profissionais que constroem juntos o cuidado em saúde, a partir dos múltiplos saberes, sendo dois assistentes sociais, um enfermeiro, um psicólogo, um redutor de danos e um arte educador. As equipes circulam ofertando cuidado em saúde nos territórios por meio de uma Van, com apoio de um motorista, atuando prioritariamente nas cenas públicas de uso de drogas da cidade.

Desde 2011, essas equipes estão vinculadas à Gerência da Rede de Saúde Mental (GRSAM) do município, atuando junto às pessoas em situação de rua, com prioridade às pessoas que fazem uso prejudicial de álcool e outras drogas e que estão em situação de rua, por isso a denominação de Consultório de Rua. A intenção do cuidado caminha pela lógica da ética em redução de danos, em tratamento das toxicomanias, havendo uma proximidade com o cuidado em saúde mental, mas sempre propondo um cuidado integral em proximidade com a atenção primária. "É nessa fronteira em que a droga encontra a exclusão social e a desfiliação mais radical que atua e intervém o Consultório de Rua, buscando fazer laço com os que se encontram mais apartados" (SILVA, 2015, p.144).

Em outros estados do Brasil a denominação utilizada é Consultório na Rua, onde as equipes estão vinculadas à Política de Atenção Básica.

Em consonância com a reforma psiquiátrica, o CdeR opera a partir de estratégias de cuidados no território, sob a ética da redução de danos e da defesa da liberdade. Fazer campo, como é denominado a entrada nas cenas de uso pelas equipes, com entrega de insumos de redução de danos, com a escuta e com intervalos de uso, implica em sustentar uma clínica a céu aberto, como afirma Rosimeire Silva

\footnotetext{
na van usuários e equipe se encontram, dialogam, planejam e realizam cuidados, projetos e atividades. A van é também endereço, a ela e a seus tripulantes são endereçados, muitas vezes, por outros usuários e pela comunidade, sujeitos em busca de cuidado (SILVA, 2015, p. 144).
}

O processo de vulnerabilização vivenciado pelas pessoas em situação de rua é marcado pela violência em suas mais diversas formas, passando por violência psicológica até violência física. Estar nas ruas faz com que esses sujeitos, a todo momento invisibilizados pela sociedade, comecem a buscar formas de se manterem vivos, utilizando recursos de sobrevivência para a superação dos obstáculos que a cidade impõe.

Entendendo que a situação de rua é inerente ao capitalismo e às expressões da questão social, se faz urgente e necessária a mudança do modo de produção vigente e a construção de uma nova sociabilidade. Como afirma Rachel Passos "A luta 'por uma sociedade sem 
manicômios' coloca-se contrária às desigualdades de classe, gênero, raça/etnia e a favor da superação da propriedade privada" (PASSOS, 2017, p. 83).

Dessa forma, o equipamento CdeR se inscreve em uma posição de garantia de direitos constitucionais já postos, na luta de acesso a esses direitos pela população em situação de rua, pela sua autonomia e visibilidade.

\section{ATUAÇÃO NA PANDEMIA}

Desde março de 2020, com o advento da pandemia as equipes começaram a trabalhar em formato de escala, com apenas dois técnicos em campo e os outros 4 em teletrabalho e retaguarda. Desde o início da pandemia, toda a equipe trabalha com os equipamentos de proteção (máscaras, luvas e quando necessário o capote), algo que inicialmente dificultava a identificação da equipe pelos usuários, mas com o passar do tempo foi possível notar a adaptação.

Os processos de trabalho tiveram que ser revistos. Se antes era permitido transportar usuários, deixá-los entrar na van, fazer atividades coletivas, promover passeios culturais, abraçá-los em campo e apertar as mãos, nesse momento isso já não era mais possível.

Começou-se um trabalho de orientação e prevenção ao COVID-19. O que mais se ouviu foi "isso não pega em nós" (sic), "tia, não vai me abraçar? Eu não tenho doença não" (sic). Foi necessário muita conversa e diálogo, com alertas para os desdobramentos possíveis dessa doença, orientações sobre etiqueta respiratória, higienização das mãos, utilização correta das máscaras e também questionamento da existência de possiveis sintomas respiratórios para que pudéssemos realizar algum tipo de encaminhamento.

No início de abril de 2020 a Prefeitura de Belo Horizonte inaugurou o Serviço de Acolhimento Provisório e Emergencial das Pessoas em Situação de Rua (PSR) e Outras Vulnerabilidades Sociais, que tem como foco o acolhimento de pessoas com sintomas respiratórios leves e que necessitem de isolamento social. Inicialmente o serviço não contava com um espaço para deixar os carrinhos de reciclagem latividade muito comum realizada pelas PSR) e não era autorizado a entrada de animais, dificultando a adesão dos usuários a proposta do serviço. Depois de um período essas alterações foram adotadas nos espaços, permitindo a entrada de animais de estimação e com espaços para deixar os carrinhos. Algo que ainda não foi permitido é o uso de substâncias psicoativas dentro da unidade de acolhimento, ou seja, ao usuário que faz uso cotidianamente de substâncias, a abstinência é obrigatória nesse 
período de isolamento social, algo incompativel com a política de redução de danos trabalhada pelo CdR.

No que diz respeito ao acesso ao auxílio emergencial, o formato único e exclusivo de cadastro online, demonstrou como o acesso a internet ainda é para grupos privilegiados. Muitos usuários tiveram dificuldades e foi através da nossa abordagem que o cadastramento pode ser concluido, utilizando por várias vezes aparelhos celulares pessoais da equipe. Não houve um equipamento público que disponibilizou o espaço ou aparelhos tecnológicos apenas para essas demandas. Além disso, percebeu-se que um grande número de usuários estavam com pendências relacionadas a documentação civil e com o fechamento das unidades de identificação civil, o acesso dessa população ao benefício ficou bem restrito aos usuários que já tinham o bolsa família, já que o depósito era automático.

Em junho de 2020 iniciou-se a distribuição de máscaras para a população em situação de rua, juntamente com kits de higiene produzidos pelas equipes.

No mesmo mês iniciou o projeto "Canto da Rua", com iniciativa da Pastoral de Rua em Belo Horizonte, de parcerias privadas e também com o apoio de órgãos públicos. Nesse espaço é oferecido lanche, banho, corte de cabelo, lavanderia, cuidados para os animais de estimação, cuidados em saúde, orientações de prevenção ao COVID19, cuidados em saúde bucal, atendimento socioassistencial, atendimento da Defensoria Pública e do Ministério Público e regularização de documentação civil. Além disso há a possibilidade de encaminhamento para hospedagens vinculadas ao projeto. Casos com suspeita de Covid19 são encaminhados para atendimento no Centro de Saúde de referência do território. Durante 15 dias em setembro o espaço ficou fechado, pois o patrocínio privado havia acabado, mas retornou às atividades com investimentos da prefeitura. Além disso, é importante ressaltar que há um grupo significativo de voluntários operando nesse serviço, mostrando como muitas vezes a política pública se transforma em caridade, não trabalhando a perspectiva dos direitos sociais dessa população.

No final de julho, as equipes se organizaram para que três técnicos estivessem em campo e três em teletrabalho e retaguarda. Os bancos da van foram encapados, o que possibilitou a higienização dos mesmos, havendo então, a possibilidade de transportar usuários dentro da van para o deslocamento para algum serviço de saúde.

Essa organização ainda está sendo mantida. Não existe, ainda, possibilidade de realizar atividades coletivas e nem passeios pela cidade, algo recorrentemente questionado pelos 
usuários, mas que sempre entendem quando justificamos que é devido a pandemia. Ainda não há previsão de quando a equipe retornará a atuar de forma completa.

\title{
DISCUSSÃO
}

No dia 14 de outubro de 2020, o atual prefeito de Belo Horizonte. Alexandre Kalil disse:

\begin{abstract}
Se você der muito conforto, vamos ser muito sincero, ano que vem são 20 mil, tá certo? Então vai falar: 'gente, morador de rua bom é lá em Belo Horizonte. Morar bem (na rua) é lá em Belo Horizonte'. Então é um problema que tem que ser enfrentado com coragem. [...] A prefeitura pode um monte de coisas em um problema que não existe solução imediata porque a prefeitura não pode jogar (morador de rua) no mar ou no rio São Francisco, já que não tem mar. E morador de rua, a maioria não quer sair da rua. Esse é o problema. (KALIL, 2020).
\end{abstract}

A perpetuação de uma política higienista e que maquia a cidade para que o excluido não apareça ainda é muito defendida na prática de alguns gestores. Pensar que a população em situação de rua é vista como um problema que precisa ser solucionado é desconsiderar que existem seres humanos, com histórias de vida e considerar que esses sujeitos não podem ocupar espaços públicos, impossibilitando o trânsito deles e muitas vezes dificultando o seu modo de existir.

Outra política higienista marcante dos governos anteriores na cidade fica perceptivel quando andamos pela região central de Belo Horizonte e percebemos a parte inferior dos viadutos, onde muitas pessoas em situação de rua dormiam, foram cobertas de pedras, os bancos das praças receberam divisórias de ferro, justamente para impedir a permanência desses sujeitos nos espaços públicos.

Quando o prefeito afirma que "a maioria não quer sair da rua", não se leva em consideração que $\mathrm{BH}$ tem apenas dois abrigos de acolhimento noturno, em condições precárias para cobrir toda a cidade. Não se investe em unidades de acolhimento para a população de rua, que muitas vezes é captada pelas ofertas sociais de moradia, alimentação, segurança das comunidades terapêuticas.

A fragilidade das políticas públicas para essa população ainda é grande. A necropolítica engendrada em nossa sociedade está escancarada quando a oferta de políticas públicas não contempla de forma integral uma população, escolhendo quem vai viver e quem vai morrer. pelas condições precárias de manutenção da vida que ofertamos.

Parece provável que passaremos a ver no próximo ano um cenário doloroso no qual algumas criaturas humanas afirmam seu direito de viver ao custo de outras, reinscrevendo a distinção espúria entre vidas passiveis e não passiveis de luto, isto é, entre aqueles que devem ser protegidos contra a morte a qualquer custo e aqueles 
cujas vidas são consideradas não valerem o bastante para ser salvaguardadas contra a doença e a morte. (BUTLER, 2020)

Quando o presidente Bolsonaro (2020) diz "Alguns vão morrer? Vão morrer. Lamento, é a vida. Não pode parar uma fábrica de automóveis porque tem mortes no trânsito" é importante que seja feito um recorte de classe: quem são as pessoas que ele está dizendo que irão morrer com a pandemia? As pessoas vulnerabilizadas, que não possuem acesso a moradia, saneamento básico, higiene, têm alimentação precária, e muitas vezes com dificuldades em acessar o sistema de saúde são o principal alvo. Como afirma Judith Butler (2020):

A desigualdade social e econômica garantirá a discriminação do vírus. $\bigcirc$ vírus por si só não discrimina, mas nós humanos certamente o fazemos, moldados e movidos como somos pelos poderes casados do nacionalismo, do racismo, da xenofobia e do capitalismo. (BUTLER, 2020)

Recorrendo a uma comparação de tempos de doença e guerra, a história da humanidade sempre valorizou a vida e o bem estar daqueles que teriam melhores condições de combater as mazelas da época, e ao mesmo tempo aqueles que teriam melhores condições de viver, ou seja, aqueles que não são o grupo de risco. Essa política da "lógica contábil do sacrifício" foi utilizada como forma de "purificação" social, enchendo prisões, manicômios e cemitérios. (DUNKER, 2020)

Ainda sobre a posição do atual presidente Jair Bolsonaro na pandemia, foram recorrentes falas em que banaliza o vírus, pontuando que "era só uma gripezinha", ou que ele mesmo não sofreria com a doença devido ao seu "histórico de atleta". As declarações foram feitas justamente em um momento onde o número de mortos no país alcançava recordes diários. A trivialização da morte, por parte de políticos como o presidente, só é possível "porque na própria fantasia descansa em um lugar de proteção divina e de especialidade" (DUNKER, 2020, p.15). Daqueles que podem repetir tranquilamente que esse mal social e viral não o atingirá, justamente pelo seu suporte médico e familiar. É aqui que a decisão politica encontra o cálculo perverso de quem pode e tem condições de viver.

Além das falas, o presidente brasileiro ainda teve diversas aparições sem o uso da máscara, equipamento de proteção que se tornou uma das principais marcas ao combate do novo coronavírus. O EPI em si, nesse caso, representa mais a proteção do outro do que do próprio sujeito, simbolizando o caráter do cuidado e da solidariedade social na travessia dessa crise sanitária. Se o ponto do debate era: a vida ou a economia, Zizek nos alerta para o 
fenômeno do animismo capitalista, onde os mercados, o capital financeiro e a economia, passam a ser entidades vivas, que nesse momento valem mais que a vida humana. (ZIZEK, 2020)

A precariedade das ofertas para a população em situação de rua se traduz em uma necropolitica dos atuais governos, que afeta diretamente a vida e as condições colocadas para esses individuos existirem. O consultório de rua é um ponto de apoio para que o acesso aos direitos dessa população sejam minimamente garantidos e mesmo com a existência desse equipamento na cidade, pode-se afirmar que ainda é muito pouco e muito frágil a forma de cuidado, que por mais que exista desejo e vontade, existe também uma barreira do sistema, que não permite o vislumbre de um cenário que não seja marcado pela violência desses corpos

\section{CONSIDERAÇÕES FINAIS}

Frente às dificuldades já existentes no cuidado à população em situação de rua, com a resistência e o preconceito dos próprios dispositivos de saúde, assistência e segurança pública, o novo coronavírus veio como mais uma ameaça à vida desses sujeitos e com um desafio de tentarmos, junto aos usuários, construir possibilidades de prevenção e cuidado. Se a higienização das mãos era prioridade contra o COVID19, as ruas e o estado pouco oferecem banheiros públicos e espaços para esse cuidado.

Pensando na realidade de Belo Horizonte, que conta com apenas dois Centros para a população em situação de rua e um Centro Integrado de Atendimento à Mulher, que oferecem banhos, alimentação, orientação psicossocial, é importante notar que são locais que se concentram na região central da cidade, centralizando esse cuidado apenas para aquele território, desassistindo outras regionais da cidade.

As frágeis possibilidades de cuidado que são ofertadas marcam o desinvestimento das políticas para pessoas em situação de rua, problema que também atinge o Consultório de Rua de Belo Horizonte, que até então conta com apenas 4 equipes, deixando algumas regionais desatendidas ou com atendimento parcial.

A proposta inicial de Zizek é de uma revisão do vocabulário no enfrentamento ao COVID-19, com destaque para a "afinidade entre in-fectio e a-fectio, ou seja, entre infecção como objeto estrangeiro e estranho e afecção, como nossa capacidade de se afetar pelo outro".(DUNKER, 2020), substituindo a necropolítica e a ideia de deixar vidas marginais e 
improdutivas para trás, em prol do animismo capitalista, por uma política civilizatória, que reconhece o mercado e a economia como fenômenos sociais que servem à vida em comunidade, e não a massacram.

Nesse ponto o Consultório de Rua já trabalha nessa perspectiva, compreendendo que o cuidado da população em situação de rua vai prescindir de diversos acordos punitivistas, proibicionistas, mercadológicos e até mesmo culturais, dando lugar para uma construção ética e subjetiva que se dá no dia a dia da rua. Como se expressa no artigo, a cidade não apresenta recursos urbanos, sanitários e assistenciais para a garantia dos direitos e respeito a essas formas de existência, o consultório de rua e os dispositivos parceiros para atendimentos dessa população, são recursos mínimos produzidos pelas políticas públicas por vezes higienista, por vezes insuficientes, e recorrentemente necropoliticas.

\section{REFERÊNCIAS BIBLIOGRÁFICAS}

BOLSONARO, Jair In: MOTA, Erick. Bolsonaro sobre coronavírus: "Alguns vão morrer, lamento, essa é a vida". Jornal Congresso em Foco, 2020. Disponivel em: $<$ https://congressoemfoco.uol.com.br/governo/bolsonaro-sobre-coronavirus-alguns-vaomorrer-lamento-essa-e-a-vida/>. Acesso em 15/10/2020.

BRASIL, Constituição (1988). Constituição da República Federativa do Brasil. Brasilia: Senado, 1988.

BRASIL. Ministério da Saúde. Portaria no 122, de 25 de janeiro de 2011. Define as diretrizes de organização e funcionamento das Equipes de Consultório na Rua. Disponível em: $\langle$ http://bvsms.saude.gov.br/bvs/saudelegis/gm/2012/prt0122_25_01_2012.html〉. Acesso em: $27 / 07 / 2020$

BUTLER, JUDITH. O capitalismo tem seus limites. Boitempo, 20/03/2020. Disponível em <https://blogdaboitempo.com.br/2020/03/20/judith-butler-sobre-o-covid-19-o-capitalismotem-seus-limites/>. Acesso em 16/10/2020

DUNKER, C. Prefácio à edição brasileira. In: ZIZEK, S, Covid-19 e a Reinvenção do Comunismo. São Paulo: Boitempo, 2020.

KALIL, Alexandre In: FIGUEIREDO. Pedro Augusto. Se der muito conforto, população em situação de rua vai aumentar, diz Kalil. Jornal $\bigcirc$ Tempo, 2020. Disponível em: <https://www.otempo.com.br/hotsites/eleicoes-2020/se-der-muito-conforto-populacao-emsituacao-de-rua-vai-aumentar-diz-kalil-1.2398802>. Acesso em: 17/10/2020. 
PASSOS, R. G.: PEREIRA, M. O. Luta Antimanicomial e Feminismos: discussões de gênero, raça e classe para a Reforma Psiquiátrica brasileira. Rio de Janeiro: Autografia, 2017.

SILVA, Rosimeire Aparecida da. Reforma psiquiátrica e redução de danos: um encontro intempestivo e decidido na construção política da clínica para sujeitos que se drogam. Belo Horizonte: 2015. Disponivel em 〈https://repositorio.ufmg.br/handle/1843/BUBDA8TMQE〉. Acesso em: $04 / 08 / 2020$

ZIZEK, S. Covid-19 e a reinvenção do comunismo. São Paulo: Boitempo, 2020. 